\title{
Blood feeding by black flies (Diptera: Simuliidae) on black grouse (Tetrao tetrix) in Finland
}

\author{
Ulriikka Ojanen, Osmo Rätti, Peter H. Adler, Kalevi Kuusela, Björn Malmqvist \& Pekka Helle
}

Ojanen, U., Rätti, O., Adler, P. H., Kuusela, K., Malmqvist, B. \& Helle, P. 2002: Blood feeding by black flies (Diptera: Simuliidae) on black grouse (Tetrao tetrix) in Finland. — Entomol. Fennica 13: 153-158.

We investigated the species composition of blood-sucking black flies harassing black grouse (Tetrao tetrix L.) by exposing live black grouse to insects in field conditions. Fieldwork was conducted in northern and central Finland in 1995 and 1996. Among identified specimens $(n=493)$ we observed five engorged black fly species: Metacnephia lyra (Lundström), Simulium (Nevermannia) vernum Macquart, Simulium (Nevermannia) bicorne Dorogostaisky, Rubtsov and Vlasenko, Simulium (Parabyssodon) transiens Rubtsov, Simulium (Eusimulium) aureum Fries, and Greniera sp. All observed species were present in northern Finland but only two of them, Simulium vernum and S. aureum, were observed in central Finland. Metacnephia lyra was the most common species harassing grouse in northern Finland. In central Finland the density was much lower, and Simulium vernum was the most prevalent. The black grouse is a novel host for all engorged species observed in this study. Also, black grouse is the first ever recorded host for Metacnephia lyra and for any member of the genus Greniera. The most likely vectors for Leucocytozoon and filarial nematodes parasitizing grouse in Finland are Metacnephia lyra and Simulium vernum in northern Finland and S. vernum in central Finland.

Ulriikka Ojanen, Finnish Game and Fisheries Research Institute, Tutkijantie 2 A, FIN-90570 Oulu, Finland

Osmo Rätti, Arctic Centre, University of Lapland, P.O. Box 122, FIN-96101 Rovaniemi,Finland;E-mail: osmo.ratti@urova.fi

Peter. H. Adler, Department of Entomology, Clemson University, Clemson, South Carolina 29634-0365, U.S.A.

Kalevi Kuusela, Oulanka Biological Station, University of Oulu, Liikasenvaarantie 134, FIN-93999 Kuusamo, Finland

Björn Malmqvist, Department of Ecology and Environmental Science, Umeå University, SE-90187 Umeå, Sweden

Pekka Helle, Finnish Game and Fisheries Research Institute, Tutkijantie 2 A, FIN-90570 Oulu, Finland

Received 21 August 2001, accepted 7 January 2002 


\section{Introduction}

The first major study of Finnish black flies (Simuliidae) was conducted by Lundström (1911). Thereafter the knowledge on Finnish black flies and their distribution has been accumulating (Carlsson 1962, Kuusela 1971, 1979, 1984, 1992, Itämies \& Kuusela 1976). In two recent checklists the number of species observed in Finland is 33 (Crosskey \& Howard 1997, Jensen 1997). The species lists are not identical and the combined total number of species is 39. In Sweden, the number of recorded species is 61 (Adler et al. 1999) and in Norway 51 (Raastad 1996). The black fly fauna of Finland is presumably still poorly known, since the number of species observed is low compared to that in adjacent areas.

Blood-sucking insects may have both direct and indirect effects on their hosts, causing itchiness and irritation. In addition to irritation black flies transmit haematozoan parasites (e.g. Desser et al. 1975, Desser \& Bennett 1993, Anderson 2000). The combined effects of physical harassment, blood parasite infection and direct loss of blood may even kill nestlings or fledglings (Hunter et al. 1997, Smith 1998). Black flies are a nuisance for various bird species, and many black fly species are specialized to feed on birds (Crosskey 1990). However, it is not well known what species of black flies are feeding on what species of birds. Also, the impact of black flies on birds and the knowledge of different host species of black flies are far from complete.

Different species of birds are often infected with haematozoan parasites (e.g. Eide et al. 1969 , Greiner et al. 1975, Peirce 1981). The two most common blood parasites occurring in the black grouse (Tetrao tetrix L.) in Finland are Leucocytozoon lovati and filarial nematodes (Höglund et al. 1992, pers. obs.). All, except one species of Leucocytozoon, are transmitted exclusively by black flies (Desser \& Bennett 1993). Filarial nematodes are transmitted by different haematophagous insects including black flies (Anderson 2000). Since black grouse are not migratory but are still infected with blood parasites transmitted by black flies, we expected that ornithophilic black flies feed on them during summer.

We investigated the species composition of blood-sucking insects harassing black grouse by exposing live black grouse to insects in field conditions. Studies on black flies feeding on a particular host are important to demonstrate possible specific black fly - host relationships and also to reveal potential haematozoan vectors for a host species. The knowledge on black fly — avian host relationships is based largely on old studies (see Crosskey 1990). Thereafter the taxonomy has developed and some earlier identifications are suspect. This study is one of the few recent studies that clearly demonstrate a black fly-avian host relationship.

\section{Methods}

We conducted the fieldwork at the Meltaus Game Research Station, Finnish Game and Fisheries Research Institute $\left(66^{\circ} 55^{\prime} \mathrm{N}, 25^{\circ} 15^{\prime} \mathrm{E}\right)$ and the Konnevesi Research Station, University of Jyväskylä $\left(62^{\circ} 37^{\prime} \mathrm{N}, 26^{\circ} 20^{\prime} \mathrm{E}\right)$ in 1995 and 1996. In 1995, the fieldwork was conducted from 20 July to 7 August in Meltaus and from 31 July to 4 August in Konnevesi. In 1996, the dates were from 27 June to 22 August in Meltaus and from 18 June to 7 August in Konnevesi.

In collecting insects we used the method developed by Bennett (1960) and Anderson \& DeFoliart (1961). Black grouse were exposed to blood-sucking insects in a cage $(56 \mathrm{~cm} \times 29 \mathrm{~cm} \times 28 \mathrm{~cm})$ for 30 -min periods. The cage was placed on the ground. At the end of each presentation, the cage was covered by a dark opaque sack. At one side of the cage there was an opening that led to a transparent container. When the cage was put at a well-illuminated place for $20 \mathrm{~min}$, the insects flew to the container after completing their blood meal. Thereafter the insects were collected from the container and preserved in $70 \%$ alcohol. The number of trials in Meltaus and Konnevesi were 57 and 60 in 1995, respectively, and 54 and 36 in 1996. In Meltaus we used six different black grouse individuals and respectively 12 individuals in Konnevesi. Trials were conducted in various habitats including spruce swamp, pine bog, and spruce, pine and birch forests. In both areas there was one large river with rapids and several smaller rivers within a radius of $10 \mathrm{~km}$ from the study site. The distances to the large river was $1 \mathrm{~km}$ in Konnevesi and $6 \mathrm{~km}$ in Meltaus.

In the laboratory we identified the insects and determined whether they were engorged or not. In this article we present a report on the black fly fauna only. Black flies were identified morphologically using keys by Ussova (1964), Rubtsov (1969), Yankovsky (1979) and unpublished keys of PHA. Taxonomic classification of black flies follows that of Crosskey \& Howard (1997). In the first stage, UO identified a sample of black flies collected in $1995(n=87)$ and samples of engorged black flies from three days in 1996 $(n=122)$ from Meltaus. All specimens from Konnevesi were identified $(n=35)$. In the second stage, we wanted to 
confirm the identifications and PHA identified 249 additional black flies of which 181 were engorged. The total number of identified black flies was thus 493 .

\section{Results}

The total number of insects collected during the study was 4342 . Ninety-nine percent $(n=4303)$ of blood-sucking insects were black flies. In addition, we observed some mosquitoes (Culicidae, $n=36$ ) and biting midges (Ceratopogonidae, $n=3$ ). Here we report the black fly fauna based on a sample from the total material. The rest of the material will be used to study seasonal variation in black fly harassment and the influence of black flies on the grouse behaviour. There were up to 300 black flies harassing the exposed grouse during a 30-minute exposure at times when black fly density was highest.

Among identified specimens we observed five different engorged black fly species: Metacnephia lyra (Lundström), Simulium (Nevermannia) vernum Macquart, Simulium (Nevermannia) bicorne Dorogostaisky, Rubtsov and Vlasenko, Simulium (Parabyssodon) transiens Rubtsov, Simulium (Eusimulium) aureum Fries, and Greniera sp. (Tables 1 and 2).
The following combination of characters indicated the unmistakable assignment of our material to the genus Greniera: the costal vein has fine light-colored setae without dark spinules, the radial vein has hair dorsobasally, the radial sector is not forked, the calcipala is small and pointed, the pedisulcus is represented by nothing more than superficial wrinkles, and the claws each have a basal thumblike lobe.

All observed species were present at Meltaus but only two of them, Simulium (Nevermannia) vernum and Simulium (Eusimulium) aureum, were recorded at Konnevesi. Our identifications of $S$. vernum also might have included some morphologically very similar species (e.g. S. cryophilum (Rubtsov)).

Metacnephia lyra was clearly the most common species harassing grouse in northern Finland (Tables 1 and 2). In 1995 we observed also one female of Simulium (Simulium) truncatum (Lundström) that, however, was not engorged. In Konnevesi, the density was much lower than in Meltaus: despite almost identical sampling effort, we collected only 36 individuals compared to more than 4000 in Meltaus. In 1995, we observed only one Simulium vernum individual, while in 1996 the species was the more prevalent of the two species in central Finland (33 individuals,

Table 1. Numbers and percentages of engorged species observed in1995 and 1996 in Meltaus, northern Finland (UO).

\begin{tabular}{lrr}
\hline & \multicolumn{1}{c}{1995} & 1996 \\
\hline Metacnephia lyra & $49(90 \%)$ & $72(59 \%)$ \\
Simulium (Nevermannia) vernum & $2(4 \%)$ & $39(32 \%)$ \\
Simulium (Parabyssodon) transiens & $1(2 \%)$ & $8(7 \%)$ \\
Simulium (Eusimulium) aureum & $1(2 \%)$ & $3(2 \%)$ \\
Simulium (Nevermannia) bicorne & $1(2 \%)$ & $0(0 \%)$ \\
Total & $54(100 \%)$ & $122(100 \%)$ \\
\hline
\end{tabular}

Table 2. Black fly fauna harassing the black grouse in Meltaus, 22 July 1996 (PHA).

\begin{tabular}{lccc}
\hline & Engorged / total & $(\%)$ & $\%$ of engorged \\
\hline Metacnephia lyra & $154 / 212$ & $(85)$ & 73 \\
Simulium (Nevermannia) vernum & $19 / 25$ & $(10)$ & 76 \\
Simulium (Parabyssodon) transiens & $7 / 10$ & $(4)$ & 70 \\
Greniera sp. & $1 / 2$ & $(<1)$ & 50 \\
Total & $181 / 249$ & $(100)$ & 73 \\
\hline
\end{tabular}


94\%; Table 4.). We observed only two individuals of $S$. aureum.

There were clear seasonal changes in the black fly fauna in 1996 in Meltaus. Metacnepnia lyra dominated during the early season (July) while during the late season Simulium vernum prevailed $\left(\chi^{2}=55.23, \mathrm{df}=2, p<0.001\right)$ (Table 3). Simulium transiens and $S$. aureum were also more abundant in the late season. Also, in Konnevesi $S$. vernum and $S$. aureum were more abundant in the late season (Table 4).

\section{Discussion}

\subsection{Species}

According to our results, black flies are the most important blood-feeding insects harassing grouse in Finland. All five engorged black fly species had tarsal claws typical of ornithophilic species (Shewell 1955, Bennett 1960).

Metacnephia lyra was the most numerous black fly species in the north and dominated especially in the early season in this study. Its distribution includes Norway, Sweden, Finland, northern Russia and western Siberia (Crosskey \& Howard 1997). Larvae of Metacnephia lyra are found in great numbers in the rapids of free-flowing larger rivers in northern Sweden and Finland (Adler et al. 1999, pers. obs.), where they rapidly develop during spring and subsequently emerge as adults in mid-June (Malmqvist 1999). The males form spectacular swarms over the river rapids. The very high densities in which they occur suggest that they have great ecological importance. This is true about the larvae, which can "carpet' the substratum of rapids with aggregates having more than 100000 larvae $/ \mathrm{m}^{2}$. These might potentially be important food for salmonids, and they significantly alter particle transport in rivers (Malmqvist et al. 2001). Because of their high abundance, the adults are also likely to be ecologically significant not only as prey for insect eaters but also by attacking birds for blood. Interestingly, we observed high density far away $(6 \mathrm{~km})$ from their likely breeding river.

Simulium vernum has a very wide distribution including Finland (Crosskey \& Howard 1997). S. vernum was found at both the Meltaus and Konnevesi study sites. It was not as abundant as M. lyra in Meltaus but prevailed clearly in the late season. In Konnevesi it was the most common species.

Simulium transiens has a Holarctic distribution (Crosskey \& Howard 1997). S. transiens was most common in the late season in Meltaus. This species develops in the slowly flowing parts of large rivers, where the larvae are found on macrophyte vegetation and occurs later in the season than M. lyra.

Simulium aureum has a wide distribution in Europe and Russia (Crosskey \& Howard 1997).

Table 3. Seasonal changes in black flies feeding on the black grouse in Meltaus in 1996 (UO).

\begin{tabular}{lrrr}
\hline & \multicolumn{1}{c}{ 2 JUL } & \multicolumn{1}{c}{22 JUL } & 6 AUG \\
\hline Metacnephia lyra & $32(80 \%)$ & $37(88 \%)$ & $3(7 \%)$ \\
Simulium (Nevermannia) vernum & $8(20 \%)$ & $4(10 \%)$ & $27(68 \%)$ \\
Simulium (Parabyssodon) transiens & $0(\%)$ & $1(2 \%)$ & $7(18 \%)$ \\
Simulium (Eusimulium) aureum & $0(\%)$ & $0(\%)$ & $3(7 \%)$ \\
Total & $40(100 \%)$ & $42(100 \%)$ & $40(100 \%)$ \\
\hline
\end{tabular}

Table 4. Seasonal changes in black flies harassing the black grouse in Konnevesi in 1996 (UO).

\begin{tabular}{lrrrr}
\hline & 18 JUN & \multicolumn{1}{c}{4 JUL } & \multicolumn{1}{c}{26 JUL } & \multicolumn{1}{c}{6 AUG } \\
\hline Simulium (Nevermannia) vernum & $1(100 \%)$ & $7(100 \%)$ & $18(95 \%)$ & $7(88 \%)$ \\
Simulium (Eusimulium) aureum & $0(0 \%)$ & $0(0 \%)$ & $1(5 \%)$ & $1(12 \%)$ \\
Total & $1(100 \%)$ & $7(100 \%)$ & $19(100 \%)$ & $8(100 \%)$ \\
\hline
\end{tabular}


It was another species observed at both of our study sites, though the density was low at both.

The distribution of Simulium bicorne is Holarctic (Crosskey \& Howard 1997). Neither Crosskey \& Howard (1997) nor Jensen (1997) included Finland into its distribution range. However, Kuusela (1992) has reported the species from northeastern Finland. In our study, the species was very rare: only one individual was observed in Meltaus.

Species of the genus Greniera have never been observed in Finland before (Crosskey \& Howard 1997). The closest observation comes from Karelia, Russia (G. brachiata) (Crosskey \& Howard 1997). Our observation of Greniera from Meltaus is also the first legitimate published record for a Nordic country. However, it has recently been observed also in northern Sweden (Malmqvist unpubl.). Larvae develop in small trickles and are, therefore, easily overlooked in stream sampling. Adults may be easier to observe.

There was a marked seasonal change in species composition. Metacnephia lyra outnumbered other ornithophilic species in northern Finland, since it is the most prevalent species in the early season when the density of black flies peaks. Interestingly, the density and the number of species were low in Konnevesi. Still, the blood parasite prevalence has been observed to be rather high in central Finland (Höglund et al. 1992, pers. obs.). This observation may suggest that a low density of vectors is able to sustain reasonably high prevalence of blood parasites. Alternatively, there is high local variation in black fly density depending on the occurrence of suitable streams for larval development. The landscape in Konnevesi is rather flat with many lakes, and relatively few and small streams.

\subsection{Black grouse as a host species}

This is the first study of the black fly fauna feeding on the black grouse. Thus, the black grouse is a novel host for all engorged species observed in this study.

Black grouse was the first-ever recorded host for Metacnephia lyra and for any member of the genus Greniera. All the species have a bifid claw typical of ornithophilic black flies and their mouthparts are not reduced. This study confirms that they really are ornithophilic species.

Ornithophily is a prevalent bloodsucking habit in both Simulium aureum and $S$ vernum (Davies et al. 1962, Crosskey 1990). Also Kuusela (1979) discovered $S$. aureum on the goshawk and the golden eagle. Our observations support that view.

Simulium transiens has been reported to be one of the most vicious bloodsuckers of humans, but it has not been observed near animals (Rubtsov 1969). Simulium bicorne rarely attacks humans or animals (Rubtsov 1969). Thus, black grouse is the first recorded avian host for Simulium transiens and S. bicorne. Their bifid claws suggest that earlier feeding observations on humans are only occasional, due to misidentification, or that these species are feeding upon both mammals and birds.

Interestingly, in our study the percentages of the different species engorging were nearly identical. We suggest that the most likely vectors for Leucocytozoon and filarial nematodes parasitizing grouse in Finland are Metacnephia lyra and Simulium vernum in northern Finland and Simulium vernum in central Finland. The contribution of other black fly species seems to be low. Additionally, blood-sucking insects influence the behaviour of the black grouse (Rätti et al. unpubl.). In the presence of insects, birds shake their heads, peck and scratch their feathers and move more often. This may expose individuals to predation. Clearly, more studies are needed on the role of black flies in northern ecosystems.

Acknowledgments. We thank Matti Hovi, Jorma Korhonen, Paavo Kumpu and Tiina Mäkinen for help with fieldwork. The Meltaus Game Research Station (Finnish Game and Fisheries Institute) and the Konnevesi Research Station (University of Jyväskylä) provided excellent facilities for our study. The study was supported by the Academy of Finland (to P.H., project 42153) and is a contribution of the Research Program for Finnish Grouse.

\section{References}

Adler, P. H., Malmqvist, B. \& Zhang, Y. 1999: Black flies (Diptera: Simuliidae) of northern Sweden: taxonomy, chromosomes, and bionomics. - Ent. Scand. 29: 361-382.

Anderson, J. R. \& DeFoliart, G. R. 1961: Feeding behavior and host preferences of some black flies (Diptera: Simuliidae) in Wisconsin. — Ann. Ent. Soc. 
America 54: 716-729.

Anderson, R. C. 2000: Nematode parasites of vertebrates: Their development and transmission, 2nd edition. CABI publishing, Oxon.

Bennett, G. F. 1960: On some ornithophilic blood-sucking Diptera in Algonquin Park, Ontario, Canada. - Can. J. Zool. 38: 377-389.

Carlsson, G. 1962: Studies on Scandinavian black flies (Fam. Simuliidae Latr.). — Opusc. Ent. 21(Suppl.): 1-280.

Crosskey, R. W. 1990: The natural history of blackflies. Wiley \& Sons Ltd, Chichester.

Crosskey, R. W. \& Howard, T. M. 1997: A new taxonomic and geographical inventory of world blackflies (Diptera: Simuliidae). - The Natural History Museum, London.

Davies, L., Downe, A. E. R., Weitz, B. \& Williams, C. B. 1962: Studies on black flies (Diptera: Simuliidae) taken in a light trap in Scotland. II. Blood meal identification by precipitin tests. - Trans. R. Ent. Soc. Lond. 114: $21-27$.

Desser, S. S. \& Bennett, G. F. 1993: The genera Leucocytozoon, Haemoproteus and Hepatocystis. - In: Kreier, J. P. (ed.), Parasitic protozoa, 2nd edition 4: 273-307. Academic Press, San Diego, California.

Desser, S. S., McIver, S. B. \& Jez, D. 1975: Observations on the role of simuliids and culicids in the transmission of avian and anuran trypanosomes. - Int. J. Parasitol. 5: 507-509.

Eide, A., Fallis, A. M., Brinkman, A. Jr., Allen, T. \& Eligh, D. 1969: Haematozoa from Norvegian birds. - Univ. Bergen Årb. Mat. Nat. Vit. 6: 1-8.

Greiner, E. C., Bennett, G. F., White, E. M. \& Coombs, R. F. 1975: Distribution of the avian hematozoa of North America. — Can. J. Zool. 53: 1762-1787.

Höglund, J., Alatalo, R. V. \& Lundberg, A. 1992: The effects of parasites on male ornaments and female choice in the lek-breeding black grouse (Tetrao tetrix). Behav. Ecol. Sociobiol. 30: 71-76.

Hunter, D. B., Rohner, C. \& Currie, D. C. 1997: Mortality in fledgling great horned owls from black fly hematophaga and leucocytozoonosis. - J. Wildl. Dis. 33: 486491.

Itämies, J. \& Kuusela, K. 1976: Black flies (Dipt., Simuliidae) collected with a light-trap on the outermost island outside Rauma (SW Finland). - Ann. Ent. Fenn. 42: 33-37.
Jensen, F. 1997: Diptera Simuliidae, blackflies. - In: Nilsson, A.N. (ed.), Aquatic insects of North Europe - a taxonomic handbook 2: 209-239. Apollo Books, Stenstrup, Denmark.

Kuusela, K. 1971: Preliminary notes on the blackfly species (Dipt., Simuliidae) of Finland. - Ann. Ent. Fenn. 37: 190-194.

Kuusela, K. 1979: Records of blood sucking blackflies (Diptera: Simuliidae) on birds of prey (Aves: Falconiidae). — Aquilo Ser. Zool. 19: 77-80.

Kuusela, K. 1984: Simuliidae (Diptera) of Inari Lapland. - Kevo Notes 7: 75-77.

Kuusela, K. 1992: Blackflies (Diptera, Simuliidae) of the biological province of Koillismaa (Ks), NE Finland. - Oulanka Reports 10: 41-43.

Lundström, C. 1911: Beiträge zur Kenntniss der Dipteren Finlands. VII. Melusinidae (Simuliidae). — Acta Soc. Fauna Flora Fenn. 34: 1-23.

Malmqvist, B. 1999: Life history of Metacnephia lyra, a blackfly highly characteristics of large Swedish river rapids at the time of maximum discharge (Diptera: Simuliidae). - Aquatic Insects 21: 89-99.

Malmqvist, B., Wotton, R. S. \& Zhang, Y. 2001: Suspension feeders transform massive amounts of seston in large northern rivers. — Oikos 92: 35-43.

Peirce, M. A. 1981: Distribution and host-parasite checklist of the haematozoa of birds in Western Europe. - J. Nat. Hist. 15: 419-458.

Raastad, J. E. 1996: Simuliidae Knott. — In: Aagaard \& Dolmen (eds), Limnofauna norvegica: Katalog over norsk ferskvannsfauna: 206-209. Tapir, Trondheim.

Rubtsov, I. A. 1969: Short keys to the bloodsucking Simuliidae of the USSR. — Israel Program for Scientific Translations, Jerusalem.

Shewell, G. E. 1955: Identity of the black fly that attacks ducklings and goslings in Canada (Diptera: Simuliidae). — Canadian Entomologist 87: 345-349.

Smith, R. N., Cain, S. L., Anderson, S. H., Dunk, J. R. \& Williams, E. S. 1998: Blackfly-induced mortality of nestling red-tailed hawks. - Auk 115: 368-375.

Ussova, Z. V. 1964: Flies of Karelia and Murmansk region. — Israel Program for Scientific Translations, Jerusalem.

Yankovsky, A. V. 1979: Two new species of genus Cnetha (Diptera, Simuliidae). — Entomol. Rev. 58: 100-105. 